\title{
Modelling of a Two-Stage Bidirectional AC-DC Converter using Wavelet Modulation
}

\author{
H.K. Chiu', Agileswari K. Ramasamy ${ }^{2}$, Nadia M.L. Tan ${ }^{3}$, Matthew Y.W. Teow ${ }^{4}$ \\ ${ }^{1,3}$ Department of Electrical Power Engineering, Universiti Tenaga Nasional, Malaysia \\ ${ }^{2}$ Department of Electronics and Communication Engineering, Universiti Tenaga Nasional, Malaysia \\ ${ }^{4}$ Faculty of Engineering and Computing, First City University College, Malaysia
}

\begin{tabular}{l} 
Article Info \\
\hline Article history: \\
Received May 3, 2018 \\
Revised Jul 20, 2018 \\
Accepted Jul 28, 2018 \\
\hline Keyword: \\
Bidirectional AC-DC converter \\
Half-bridge CLLC resonant \\
Converter \\
Resonant converter \\
Wavelet modulation
\end{tabular}

Article Info

rticle history:

Received May 3, 2018

Revised Jul 20, 2018

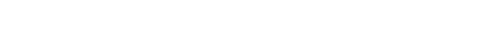

\begin{abstract}
In this paper, a Wavelet modulated isolated two-stage three-phase bidirectional AC-DC converter is proposed for electric vehicle (EV) charging systems. Half-bridge resonant CLLC converter is proposed due to its high efficiency, wide gain range, galvanic isolation and bidirectional power flow. Wavelet modulation technique is used for three-phase six leg AC-DC converter due to its benefits of high DC component and lower harmonic contents. The proposed two-stage converter is developed and simulated in MATLAB Simulink environment. The contribution of this paper is on the implementation and performance analysis of Wavelet modulation in bidirectional AC-DC converters. The results show that Wavelet modulation is suitable to be implemented for the proposed bidirectional converter. The performance of the proposed converter delivers very low output voltage ripple and total harmonic distortion output current of less than $10 \%$ which is within the expected results.
\end{abstract}

Copyright $@ 2018$ Institute of Advanced Engineering and Science. All rights reserved.

\section{Corresponding Author:}

H.K. Chiu,

Department of Electrical Power Engineering,

Universiti Tenaga Nasional,

Jalan Ikram-Uniten, 43000 Kajang, Selangor Darul Ehsan, Malaysia

Email: PE20689@utn.edu.my

\section{INTRODUCTION}

Electric vehicle (EV) has gained much attention in the last decade as a promising solution to greenhouse gas (GHG) emissions in the transportation sector. One of its main advantages is to reduce dependency on fossil fuels as a source of fuel supply for vehicles. EVs also have the benefits of providing additional support to the electric power grid such as ancillary services and load balancing [1]. For EVs to compete with conventional combustion engine performance, high efficiency of EV chargers are required to deliver optimum performance and energy saving for the consumers. There are many different converter topologies and systems proposed for single-stage and two-stage topologies [1]-[8]. Two-stage topologies have the disadvantage of increased cost and size due to having two stages of energy conversion however, this has the advantage of having a fixed DC link voltage, simplifying the DC-DC converter [1]-[2].

Wavelet modulation is a modulation strategy that is currently used in inverters and multilevel inverters [10]-[14]. The advantages of wavelet modulation compared to existing modulation techniques is that it does not require a carrier signal, generates a higher magnitude of the fundamental component in the output voltage and lower harmonic distortion compared to other pulse width modulation (PWM) methods such as sinusoidal PWM (SPWM), space vector PWM (SVPWM), phase shifted PWM (PSPWM) and level shifted PWM (LSPWM) [13],[15]. Therefore, the contribution of this paper is on the implementation and performance analysis of Wavelet modulation in bidirectional AC-DC converters and also a new two-stage topology that can be implemented for bidirectional EV chargers. 
In this paper, a two-stage bidirectional AC-DC converter is proposed, using six switch AC-DC converter and half-bridge CLLC resonant converter. Previous studies have shown that half bridge CLLC resonant converters are able to provide high power density, high efficiency, and the additional capacitors in each leg allows reduction of flux imbalance for the transformer [3]-[6]. The proposed converter has two converters, the bidirectional AC-DC converter connected to a three-phase grid and DC voltage link controlled using Wavelet modulation and a half-bridge CLLC resonant converter controlled using frequency modulation. The following chapters of this paper would elaborate on the wavelet modulation strategy used, design considerations for the proposed two-stage bidirectional converter, the simulated results obtain using MATLAB Simulink, conclusion and the potential areas to improve this converter.

\section{WAVELET MODULATION CONTROL}

The wavelet modulation technique for inverters has been implemented using sampling theorem and nondyadic-type multiresolution analysis (MRA) [11]-[15]. The signals required to operate a power electronic converter is modeled and optimized using sets of newly developed scale-based linearly combined scaling and synthesis wavelet basis functions. In order to realize wavelet modulation technique which requires the nondyadic MRA to sample and reconstruct the reference signal, the analysis stage and synthesis stage is required as shown below:

Analysis Stage :The referenced signal (desired output signal) is sampled using scale-based linearly combined scaling basis, $\left\{\varphi\left(2^{j} t-k\right\}_{j, k \in \mathbb{Z}}\right.$ which develops groups of nonuniform recurrent samples that is vital in determining the width and location of one ' $\mathrm{ON}$ ' state pulse

Synthesis : The reference signal is now reconstructed from the groups of samples obtained in Stage theanalysis stage. These synthesized functions are used as ON switching states for the power electronic converter.

The three sets of groups of nonuniform recurrent samples from reference signal are as follows [12]:

$$
\begin{aligned}
& \left(\varphi_{a}(t)\right)_{j 1}=\phi\left(2^{j 1+1} t\right)+\phi\left(2^{j 1+1}\left(t-1-2^{-(j 1+1)}\right)\right) \\
& \left(\varphi_{b}(t)\right)_{j 2}=\phi\left(2^{j 2+1} t\right)+\phi\left(2^{j 2+1}\left(t-1-2^{-(j 2+1)}\right)\right) \\
& \left(\varphi_{c}(t)\right)_{j 3}=\phi\left(2^{j 3+1} t\right)+\phi\left(2^{j 3+1}\left(t-1-2^{-(j 3+1)}\right)\right)
\end{aligned}
$$

where $\mathrm{j} 1=1,2 \ldots, \mathrm{J}, \quad \mathrm{j} 1 \in \mathbb{Z}, \mathrm{j} 2=\mathrm{j} 1+\mathrm{J}-3, \mathrm{j} 2 \in \mathbb{Z}, \mathrm{j} 3=\mathrm{j} 1+\mathrm{J}-2, \mathrm{j} 3 \in \mathbb{Z}$ and $\mathrm{J}$ is the maximum value of $\mathrm{j}$.

The reconstruction of reference signal is accomplished with three synthesis basis functions which are generated by the shifted versions of Equation 1 to 3 . The three synthesis scaling functions are defined as follow [12]:

$$
\begin{aligned}
& \left(\tilde{\varphi}_{a}(t)\right)_{j 1}=\phi_{H}(t)-\left(\varphi_{a}(t)\right)_{j 1} \\
& \left(\tilde{\varphi}_{b}(t)\right)_{j 2}=\phi_{H}(t)-\left(\varphi_{b}(t)\right)_{j 2} \\
& \left(\tilde{\varphi}_{c}(t)\right)_{j 3}=\phi_{H}(t)-\left(\varphi_{c}(t)\right)_{j 3}
\end{aligned}
$$

where $\phi_{H}(t)$ is the Haar scaling function [13] and $\tilde{\varphi}(t)$ is the scale-based linearly combined function. The nondyadic type MRA representation of three continuous time (CT) reference modulating signals for the output voltage of each phase (inverter) with respect to the DC voltage is shown below [13]:

$$
\frac{v_{a}(t)}{V_{D C}}=\sum_{j=1}^{J}\left(\tilde{\varphi}_{a}(t)\right)_{j}-\left(\tilde{\varphi}_{a}\left(t-\frac{T_{m}}{2}\right)\right)_{j}+\sum_{j=1}^{J-1}\left(\tilde{\varphi}_{a}(t)\right)_{(J-j)}-\left(\tilde{\varphi}_{a}\left(t-\frac{T_{m}}{2}\right)\right)_{(J-j)}
$$




$$
\begin{aligned}
& \frac{v_{b}(t)}{V_{D C}}=\sum_{j=1}^{J}\left(\tilde{\varphi}_{b}(t)\right)_{j}-\left(\tilde{\varphi}_{b}\left(t-\frac{T_{m}}{2}\right)\right)_{j}+\sum_{j=1}^{J-1}\left(\tilde{\varphi}_{b}(t)\right)_{(J-j)}-\left(\tilde{\varphi}_{b}\left(t-\frac{T_{m}}{2}\right)\right)_{(J-j)} \\
& \frac{v_{c}(t)}{V_{D C}}=\sum_{j=1}^{J}\left(\tilde{\varphi}_{c}(t)\right)_{j}-\left(\tilde{\varphi}_{c}\left(t-\frac{T_{m}}{2}\right)\right)_{j}+\sum_{j=1}^{J-1}\left(\tilde{\varphi}_{c}(t)\right)_{(J-j)}-\left(\tilde{\varphi}_{c}\left(t-\frac{T_{m}}{2}\right)\right)_{(J-j)}
\end{aligned}
$$

where $\mathrm{T}_{\mathrm{m}}$ is the period of the sinusoidal function, $v(t)$ is the output voltage per phase and $V_{D C}$ is the input voltage. For the output voltage at DC link (Rectifier), it can be derived as shown below [12]:

$$
\begin{aligned}
S_{\mathrm{dc}}(t)= & \sum_{k \in \mathbb{Z}} \sum_{j 1}\left\langle\left\langle\left\langle S_{\mathrm{dc}}(t),\left(\varphi_{a}(t-k)\right)_{j 1}\right\rangle\right\rangle_{2},\left(\tilde{\varphi}_{a}(t-k)\right)_{j 1}\right\rangle \\
& +\sum_{k \in \mathbb{Z}} \sum_{j 2}\left\langle\left\langle\left\langle S_{\mathrm{dc}}(t),\left(\varphi_{b}(t-k)\right)_{j 2}\right\rangle\right\rangle_{2},\left(\tilde{\varphi}_{b}(t-k)\right)_{j 2}\right\rangle \\
& +\sum_{k \in \mathbb{Z}} \sum_{j 3}\left\langle\left\langle\left\langle S_{\mathrm{dc}}(t),\left(\varphi_{c}(t-k)\right)_{j 3}\right\rangle\right\rangle_{2},\left(\tilde{\varphi}_{c}(t-k)\right)_{j 3}\right\rangle .
\end{aligned}
$$

The inner biproduct operation is derived as below for Equation 10 for one of the phases:

$$
\begin{aligned}
& \left\langle\left\langle S_{\mathrm{dc}}(t),\left(\varphi_{a}(t)\right)_{j 1}\right\rangle\right\rangle_{2}=\left\{\int_{d T_{\phi}}^{t_{d a 1}} S_{\mathrm{dc}}(t) \phi\left(2^{j 1+1} t\right) d t\right. \\
& \left.\int_{t_{d a 2}}^{(d+1) T_{\phi}} S_{\mathrm{dc}}(t) \phi\left(2^{j 1+1}\left(t-1+2^{-(j 1+1)}\right)\right) d t\right\} \\
& T_{\phi}=\frac{T_{m}}{2\left(J^{2}+J\right)}
\end{aligned}
$$

where $T_{m}$ is the period of the AC input and $S_{d c}(t)$ is the reference DC voltage with respect to time. Lastly, the samples in each group (each phases) $d a, d b$ and $d c$ are located at the boundaries of $\left[t_{d a 1}, t_{d a 2}\right],\left[t_{d b 1}, t_{d b 2}\right]$ and $\left[t_{d c 1}, t_{d c 2}\right]$. The time locations are obtained to determine switching intervals for each of the phase leg. The time locations are determined as follow [14]:

$$
\begin{aligned}
& t_{d a 1}=T_{\phi}\left(d a+2^{-j 1-1}\right) \quad d a=0,1,2, \ldots, \mathcal{D}-1 \\
& \underbrace{t_{d a 2}=T_{\phi}\left(d a+1-2^{-j 1-1}\right)}_{\text {forleg1 }} \\
& t_{\text {forleg } 2}^{t_{d b 1}=T_{\phi}\left(d b+2^{-j 2-1}\right) \quad d b}=0,1,2, \ldots, \mathcal{D}-1 \\
& \underbrace{t_{d b 2}=T_{\phi}\left(d b+1-2^{-j 2-1}\right)}_{\text {forleg } 3} \\
& \underbrace{t_{d c 2}=T_{\phi}\left(d c+2^{-j 3-1}\right) \quad d c}_{d c 1}=0,1,2, \ldots, \mathcal{D}-1
\end{aligned}
$$


The key differences between modulating for rectifier operation and inverter operation are the reference signal required and how the set of groups of samples are computed based on the number of reference signals. Another notable difference is the scales $j 1, j 2$ and $j 3$. During rectifier mode, the changes are based on the input $\mathrm{AC}$ voltages while during inverter mode, it is changed based on the reference signal.

\section{DESIGN CONSIDERATIONS FOR THE PROPOSED CONVERTER}

In this paper, a two-stage bidirectional AC-DC converter is proposed, using six switch AC-DC converter and half-bridge CLLC resonant converter. The proposed converter has two converters as shown in Figure 1, where the bidirectional AC-DC converter is connected to a three-phase grid and is controlled using Wavelet modulation and a half-bridge CLLC resonant converter controlled using frequency modulation.

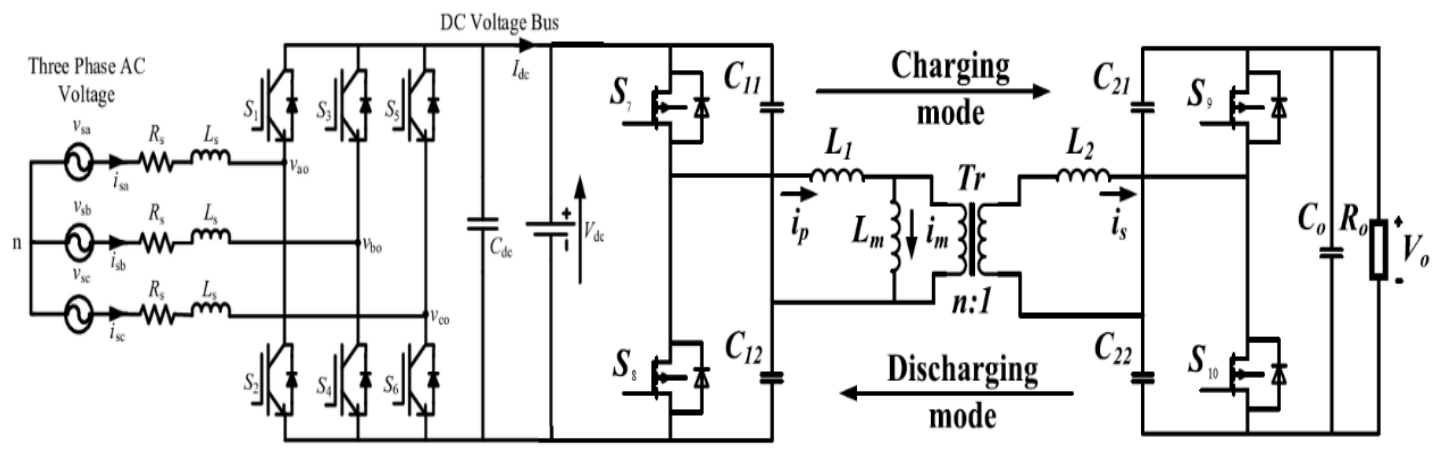

Figure 1. Proposed two-stage bidirectional AC-DC converter

The bidirectional half-bridge CLLC converter has two power flow modes: charging (power flowing from DC link voltage to the battery) and discharging (power flowing from the battery to the DC link voltage). The equivalent circuit of the half-bridge CLLC resonant converter is shown in Figure 2 for both modes. $R_{e}$, $L_{2}^{\prime}, C^{\prime}{ }_{21}$ and $C^{\prime}{ }_{22}$ are the equivalent to $R_{o}, L_{2}, C_{21}$ and $C_{22}$ of the converter respectively.

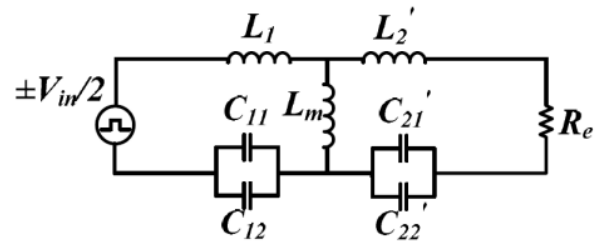

(a)

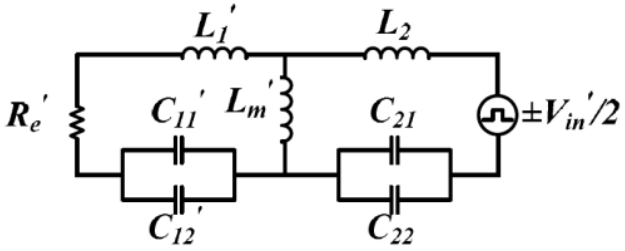

(b)

Figure 2. Equivalent circuits of half-bridge CLLC converter in

(a) charging mode and (b) discharging mode [9]

A detailed derivation for $R_{e}$ for full-bridge CLLC converter can be obtained in [4] by using First Harmonic Approximation (FHA) method. For the half-bridge CLLC converter in charging mode, the parameters can be expressed as [9]:

$$
\begin{array}{ccc}
R_{e}=\left(2 n^{2} / \pi^{2}\right) R_{o} & L_{2}^{\prime}=n^{2} L_{2} & C_{1}=C_{11}+C_{12} \\
C_{2}^{\prime}=C_{21}^{\prime}+C_{22}^{\prime} & C_{21}^{\prime}=C_{21} / n^{2} & C_{22}^{\prime}=C_{22} / n^{2}
\end{array}
$$

While the parameters during discharging mode can be calculated as [9]: 


$$
\begin{array}{ccc}
R_{e}^{\prime}=\left(2 / n^{2} \pi^{2}\right) R_{o}^{\prime} & L_{1}^{\prime}=L_{1} / n^{2} & C_{1}^{\prime}=C_{11}^{\prime}+C_{12}^{\prime} \\
C_{2}=C_{21}+C_{22} & C_{11}^{\prime}=n^{2} C_{21} & C_{12}^{\prime}=n^{2} C_{22} \\
L_{m}^{\prime}=L_{m} / n^{2} & &
\end{array}
$$

Given that the $L$ and $C$ will be of same values in both modes, the resonant frequency for both the modes will be identical.

\section{RESULTS AND ANALYSIS}

The previous sections presented the methodology to develop the time boundaries for each of the phase leg of the bidirectional AC-DC converter and the design considerations to determine the component values of the half bridge CLLC converter based on its equivalent circuit. The bidirectional three-phase six pulse AC-DC converter is modulated using Wavelet modulation technique while the half-bridge CLLC converter is controlled using frequency modulation. Simulation results were obtained using MATLAB Simulink for the rated output power of $1 \mathrm{~kW}$, as shown in Figure 3. In the blue area as highlighted in Figure 3, shows the six-switch three-phase bidirectional AC-DC converter and the Wavelet modulation block while the red area shows the half-bridge CLLC resonant converter and its frequency modulation block.

The main objective of this simulation is to investigate the features of the inputs and outputs of the proposed converter during charging and discharging mode. The design parameters and components used for the simulation is shown in Table 1. The input three phase voltage for this converter would be 415 VAC at 50 $\mathrm{Hz}$, the DC link voltage is adjusted to be $500 \mathrm{~V}$ and the output of the CLLC resonant converter is set at 250 $\mathrm{V}$. The switching frequency for the half-bridge resonant CLLC converter is set at $230 \mathrm{kHz}$. The sampling time, Ts for the simulation is set at $50 \mu \mathrm{s}$. The power electronic switches used for the bidirectional AC-DC converter are ideal IGBTs in simulation and MOSFETs with with internal diode in parallel with RC snubber circuit for the bidirectional DC-DC converter. The developed SIMULINK model of the proposed converter is tested on a load of $176 \Omega\left(\mathrm{R}_{\mathrm{O}}\right)$ [9]. The results obtained from the simulation will be displayed and discussed in this section.

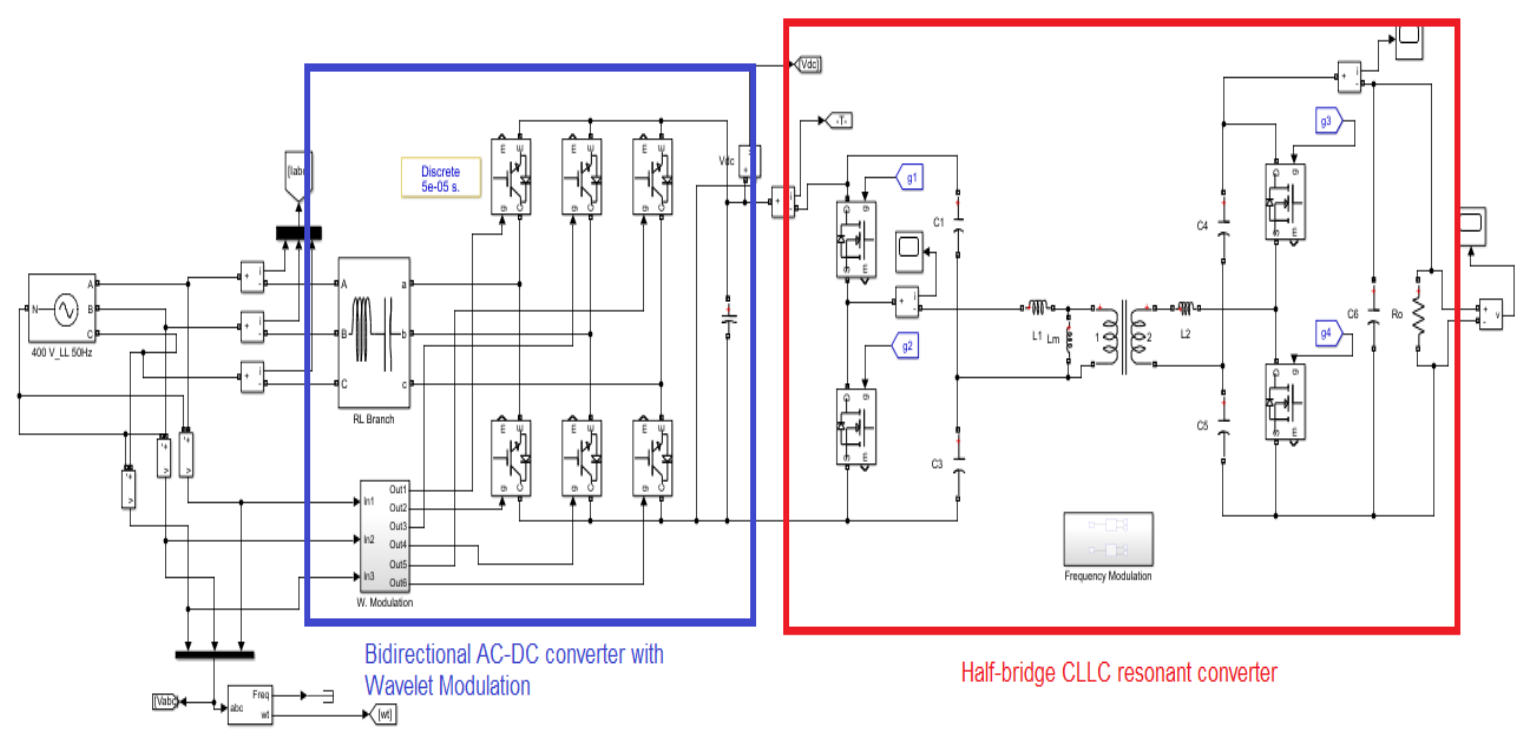

Figure 3. Simulation model of the proposed converter in Simulink

Figure 3. Simulation Model of the Proposed Converter in Simulink

\begin{tabular}{cc}
\hline Components & Values \\
\hline RL Filter & $1 \Omega$ and $10 \mathrm{mH}$ \\
DC Link Capacitor & $4700 \mu \mathrm{F}$ \\
$\mathrm{C}_{11}$ and $\mathrm{C}_{12}$ & $14.2 \mathrm{nF}$ \\
$\mathrm{L}_{1}$ & $32 \mu \mathrm{H}$ \\
$\mathrm{L}_{2}$ & $15 \mu \mathrm{H}$ \\
$\mathrm{C}_{21}$ and $\mathrm{C}_{22}$ & $33 \mathrm{nF}$ \\
$\mathrm{R}_{\mathrm{O}}$ and $\mathrm{C}_{6}$ & $176 \Omega$ and $1000 \mu \mathrm{F}$ \\
\hline
\end{tabular}


Figure 4 shows the DC link voltage output of the converter during rectifier mode. The average output DC was obtained around $520 \mathrm{~V}$. The reason why the DC voltage is higher than the expected rating of $500 \mathrm{~V}$ is due to the Wavelet modulation not having any feedback to control the output voltage. Figure 5 shows the DC link voltage during inverter mode at $500 \mathrm{~V}$. The output DC link voltage was obtained through the bidirectional CLLC resonant converter. Although there are some ripple observed in the results obtained, the root mean square (RMS) value of the voltage is still within acceptable results.

Figure 6 and 7 shows the input AC current of the proposed bidirectional AC-DC converter. The total harmonic distortion of the current (THDi) was computed in Simulink which is obtained by diving the RMS value of the total harmonics of the signal by the RMS value of its fundamental signal. The THDi obtained during rectifier mode is $7.2 \%$ while the THDi during inverter mode is $6.2 \%$. The THD results can be further reduced if optimization techniques to control the phase and current was included with the Wavelet modulation scheme at the cost of increased complexity in the control structure.

Figure 8 shows the line-to-line voltage $\mathrm{V}_{\mathrm{L}-\mathrm{L}}$ at the three-phase supply during inverter/discharging mode. The RMS value of the $\mathrm{V}_{\mathrm{L}-\mathrm{L}}$ was measured at $390 \mathrm{~V}$. The $\mathrm{THD}_{\mathrm{V}}$ obtained for this voltage is $47 \%$ which is slightly high for the current technology of inverters. One of the few ways to improve the harmonics of the result is by changing the scale $J$ to a larger value and to include filters before connecting to the grid. Figure 9 shows the output voltage of the half-bridge CLLC converter at $249 \mathrm{~V}$. The output voltage ripple of the DCDC converter is $0.02 \mathrm{~V}$ which is approximately $0.01 \%$ voltage ripple. The output voltage can be adjusted by controlling the switching frequency of the converter. The results obtained were within acceptable voltage levels. Figure 10 shows the input and output resonant transformer current of the CLLC converter during charging mode. The average output current to the load is $1.86 \mathrm{~A}$.

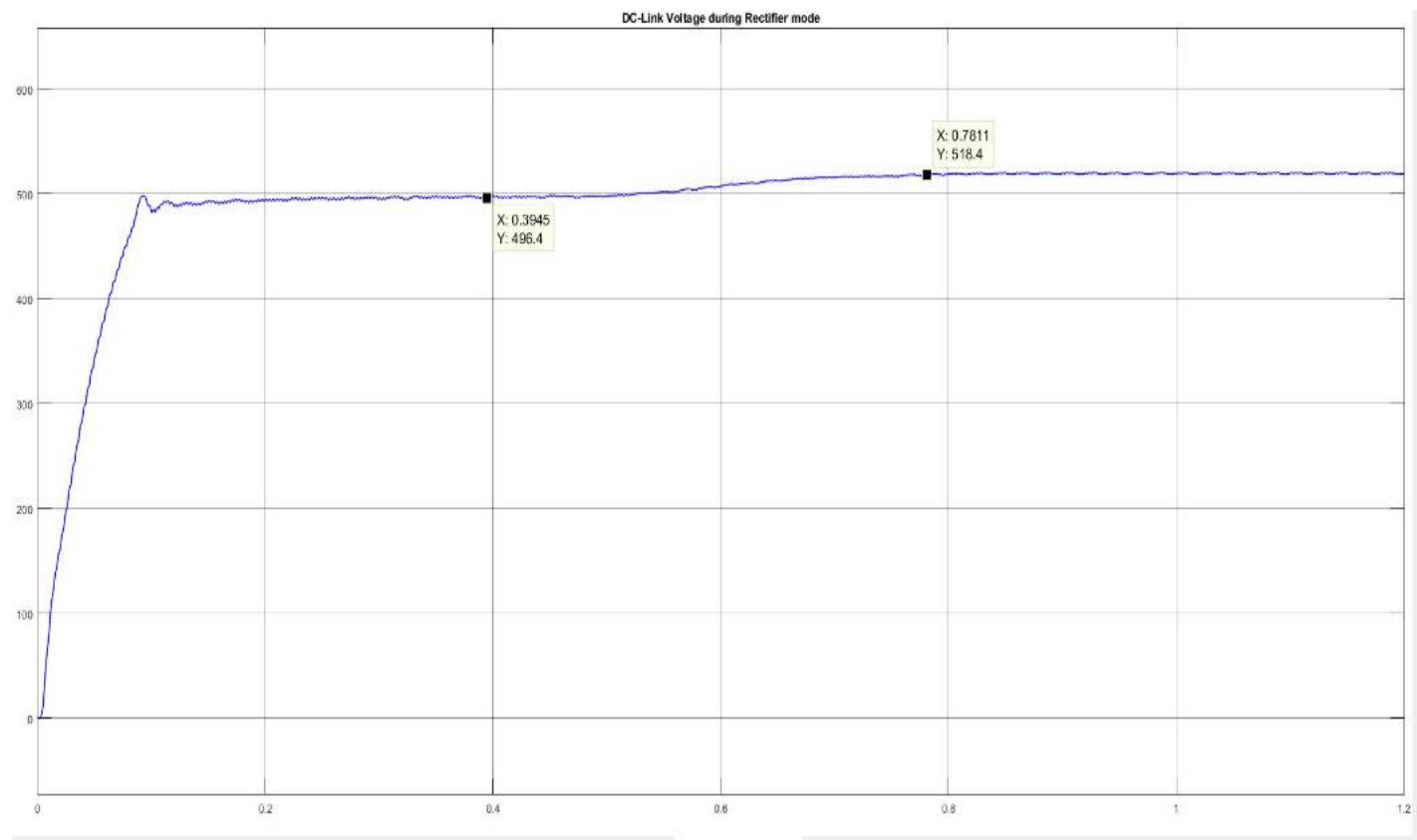

Figure 4. DC link voltage during rectifier mode 


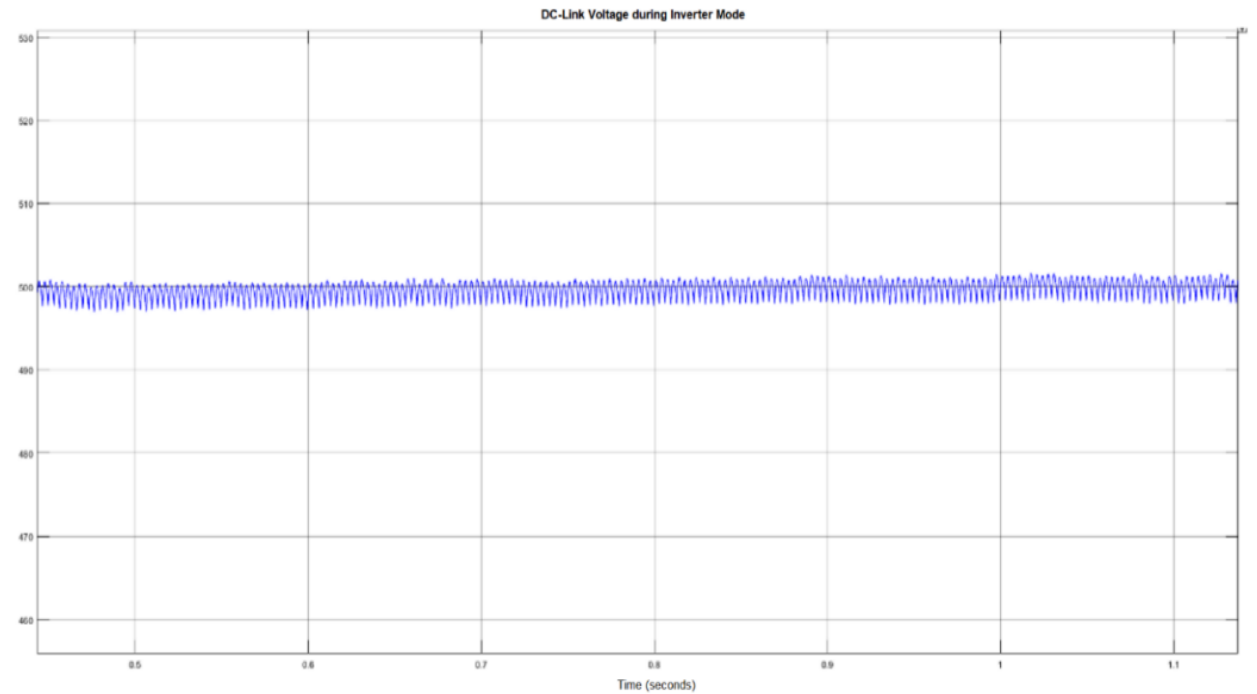

Figure 5. DC link voltage during inverter mode

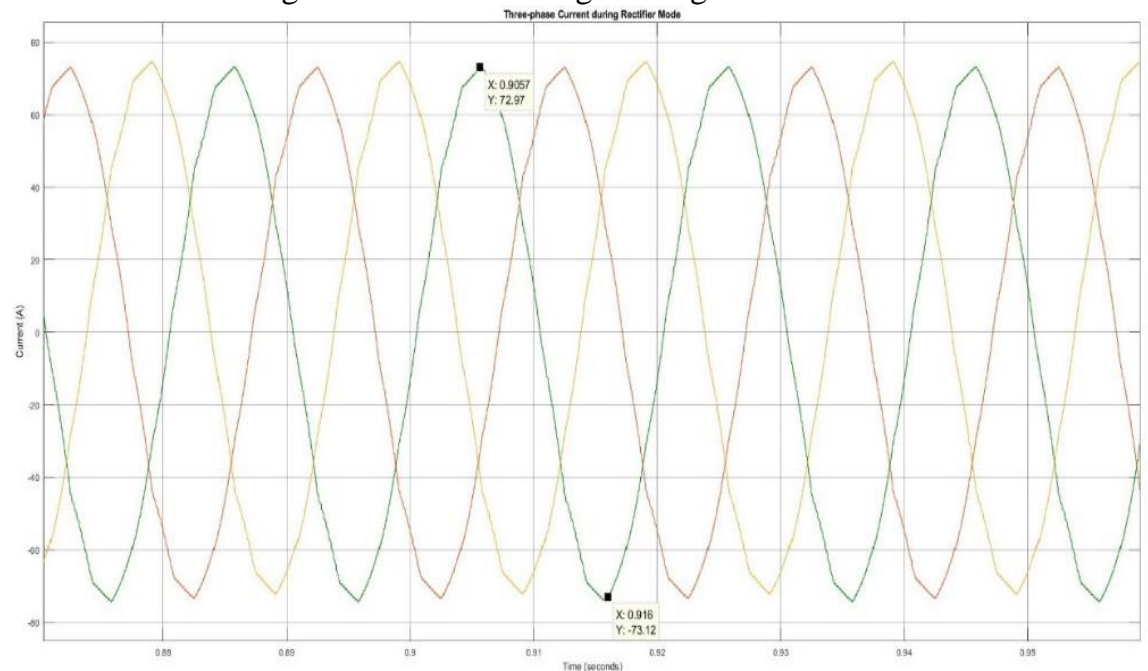

Figure 6 . Input current at 3 phase supply during rectifier mode

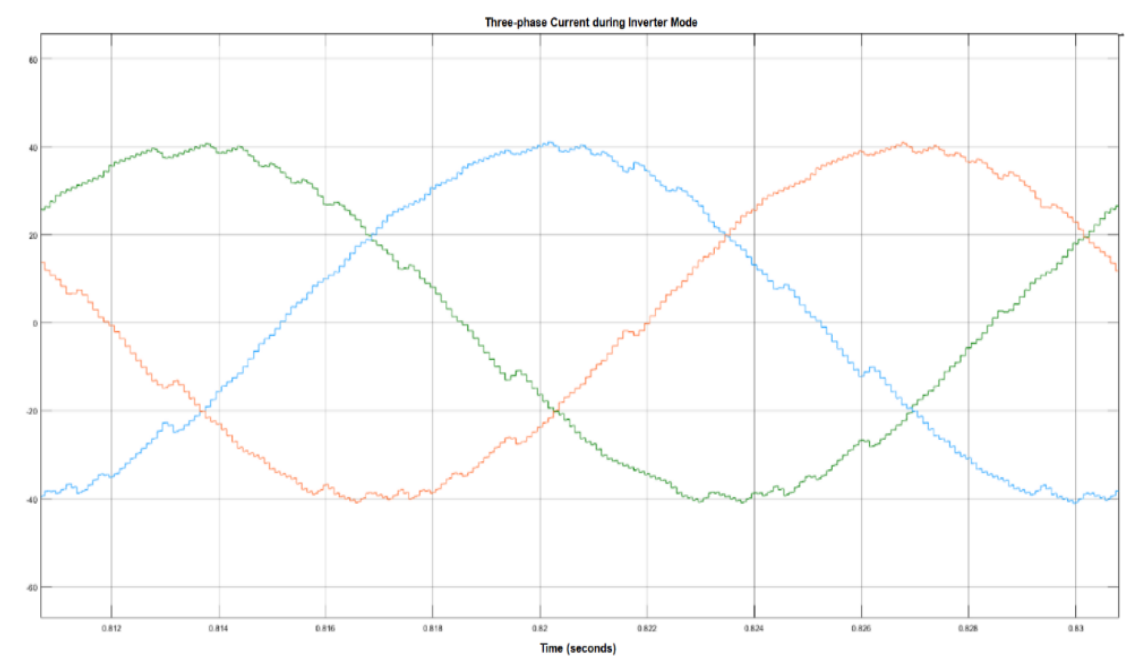

Figure 7. Output current at AC side during inverter mode 


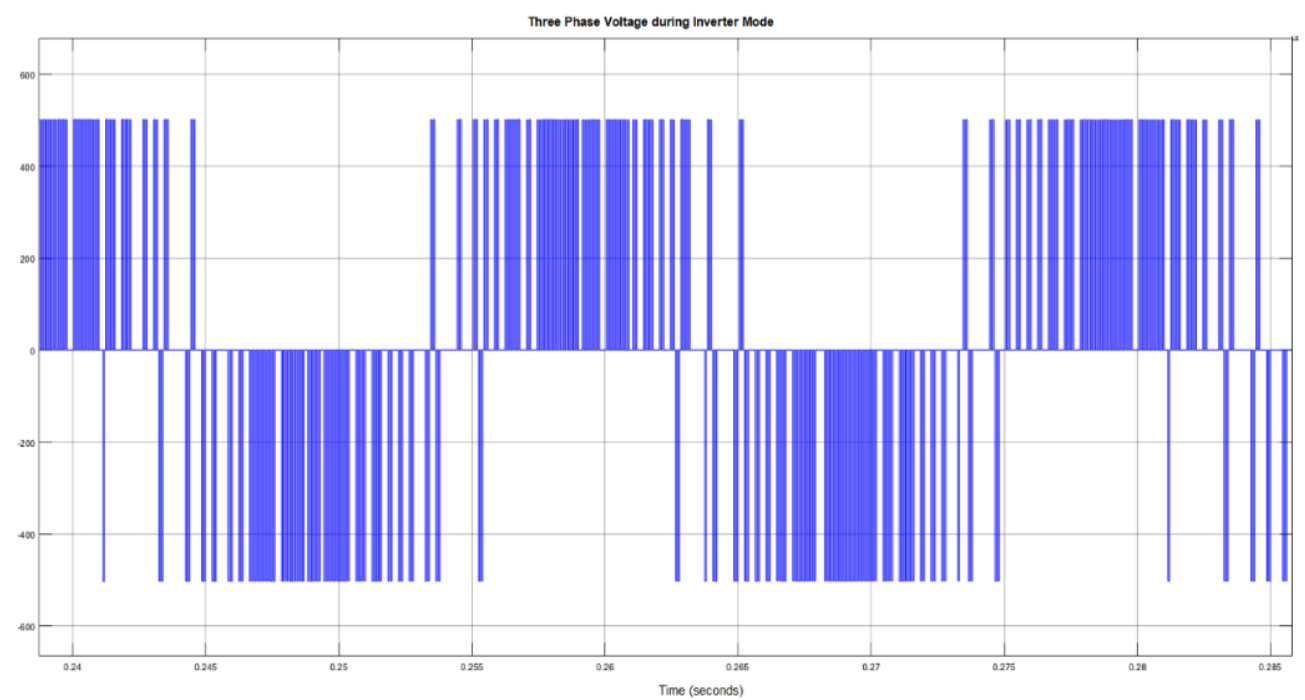

Figure 8. Output line-to-line voltage at AC side during inverter mode

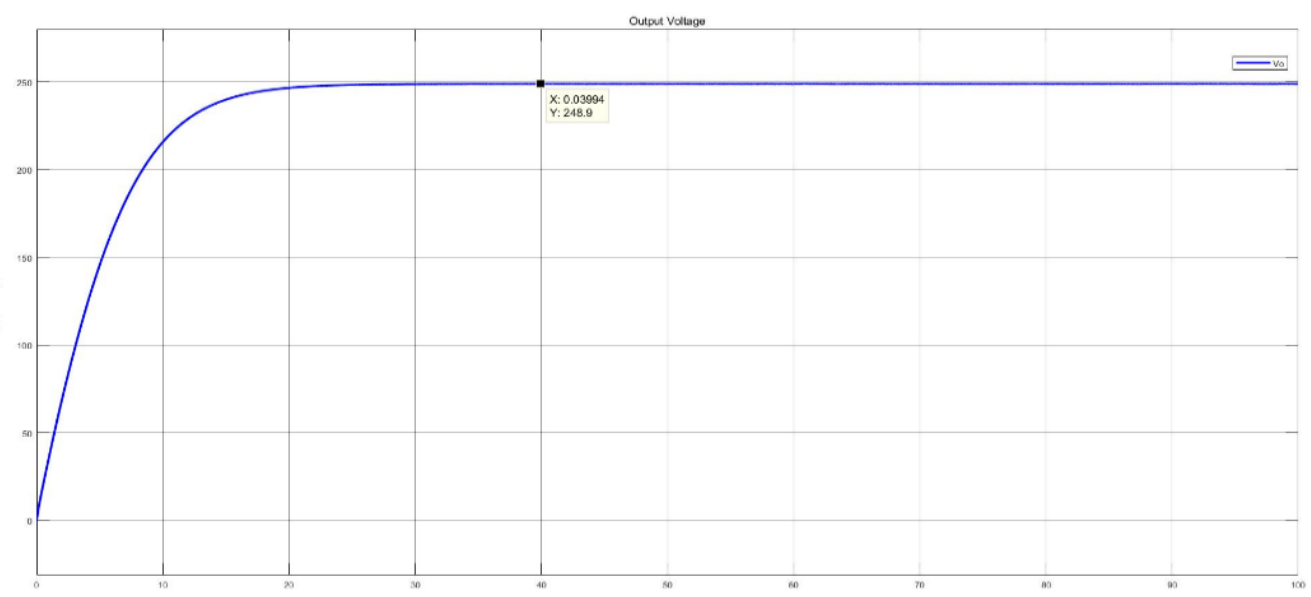

Figure 9. Output voltage of the half-bridge CLLC resonant converter at 250V
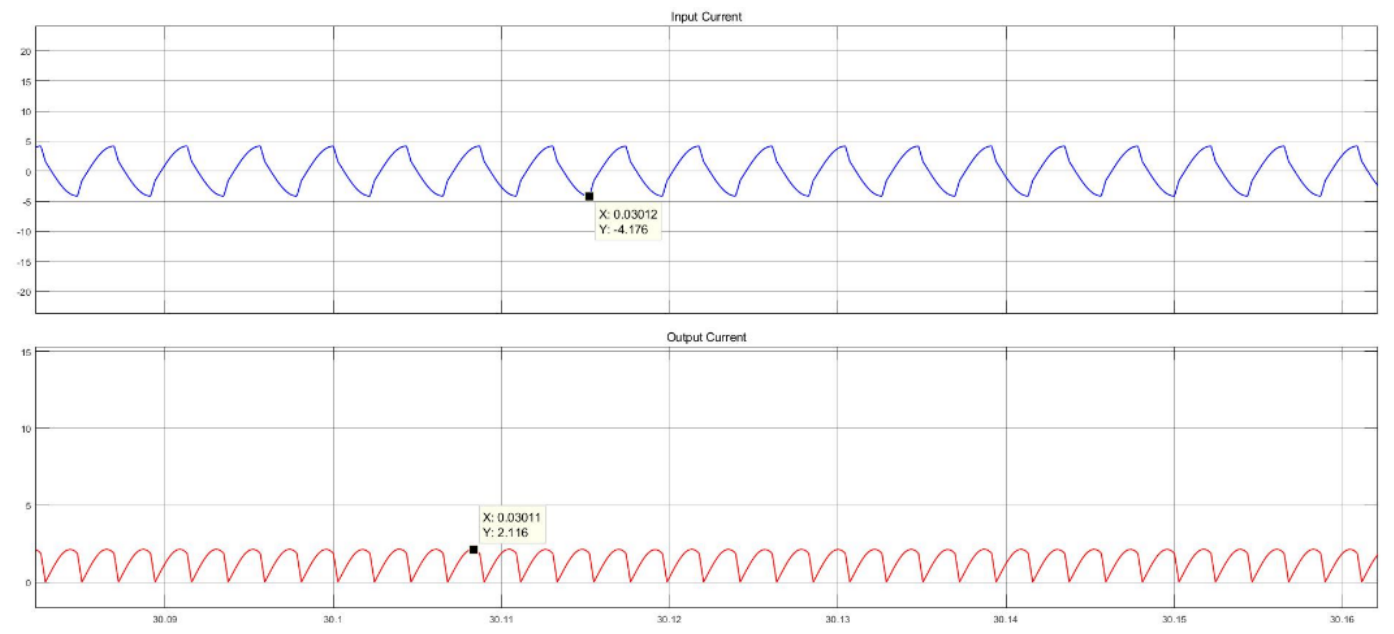

Figure 10. Input and Output current of the half-bridge CLLC resonant transformer during charging mode 
Overall, the results obtained for the proposed converter shows acceptable output results. The DClink voltage was able to maintain near $500 \mathrm{~V}$ for both rectifier and inverter mode. For the half-bridge CLLC resonant converter, the average output voltage across $R_{O}$ was obtained at $250 \mathrm{~V}$. The obtained $\mathrm{THD}_{\mathrm{i}}$ for both rectifier and inverter mode were within acceptable range of below $10 \%$. The increase in DC-link voltage as shown in Figure 4 is running in an open-loop control. The lack of output voltage feedback control to the wavelet modulation strategy thus lead the result as shown in Figure 4. To improve the accuracy and controllability of the output DC voltage, optimization to the Wavelet modulation is required such as including voltage feedback loops. The remaining results obtained are obtained within expectations. The desired output voltage and current of the CLLC converter were obtained in this simulation. The total harmonic distortion for the current and the line to line voltage obtained were well within the desired range of the proposed converter.

\section{CONCLUSION}

In this paper, a Wavelet modulated two-stage bidirectional AC-DC converter has been proposed for EV charging applications. The implementation of the wavelet modulation technique for a three-phase bidirectional AC-DC converter is based on constructing a nondyadic type MRA capable of supporting nonuniform recurrent sampling and reconstruction of the reference DC signal and AC signal. The nondyadic MRA was successfully constructed using a scale and shift based combined analysis and synthesis wavelet basis functions. The simulation performance results have demonstrated that Wavelet modulation technique can be implemented for bidirectional AC-DC converters. Most of the obtained results in the simulation were well within expectations. However, there are still room for improving the performance of the modulation strategy. The performance of Wavelet modulation can be further improved with the use of output voltage feedback control for both inverter and rectifier modes.

\section{ACKNOWLEDGEMENTS}

The authors of this paper would like to thank Institute of Power Engineering, Universiti Tenaga Nasional (UNITEN) for the financial support under the BOLD research grant, project 10289176/B/9/2017/49 and Ministry of Higher Education for the financial support under Fundamental Research Grant Scheme (FRGS) grant, project code 20150207FRGS.

\section{REFERENCES}

[1] Z. Yinhai, et al., "A Novel SVPWM Modulation Scheme," in Applied Power Electronics Conference and Exposition, 2009. APEC 2009. Twenty-Fourth Annual IEEE, 2009, pp. 128-131.

[2] Yilmaz M, Krein PT. Review of battery charger topologies, charging power levels, and infrastructure for plug-in electric and hybrid vehicles. IEEE Transactions on Power Electronics. 2013;28(5):2151-69.

[3] Park J-E, Kim J-W, Lee B-H, Moon G-W, editors. Design on topologies for high efficiency two-stage AC-DC converter. Power Electronics and Motion Control Conference (IPEMC), 2012 7th International; 2012: IEEE.

[4] He P, Khaligh A. Comprehensive Analyses and Comparison of $1 \mathrm{~kW}$ Isolated DC-DC Converters for Bidirectional EV Charging Systems. IEEE Transactions on Transportation Electrification. 2017;3(1):147-56.

[5] Jung JH, Kim HS, Ryu MH, Baek JW. Design Methodology of Bidirectional CLLC Resonant Converter for HighFrequency Isolation of DC Distribution Systems. IEEE Transactions on Power Electronics. 2013;28(4):1741-55.

[6] Zahid ZU, Dalala ZM, Chen R, Chen B, Lai J-S. Design of bidirectional DC-DC resonant converter for vehicle-togrid (V2G) applications. IEEE Transactions on Transportation Electrification. 2015;1(3):232-44.

[7] Tang Y, Lu J, Wu B, Zou S, Ding W, Khaligh A. An Integrated Dual-Output Isolated Converter for Plug-in Electric Vehicles. IEEE Transactions on Vehicular Technology. 2018;67(2):966-76.

[8] Wang H, Dusmez S, Khaligh A. Maximum efficiency point tracking technique for CLLC-based PEV chargers through variable DC link control. IEEE Transactions on Industrial Electronics. 2014;61(11):6041-9.

[9] Zou S, Lu J, Mallik A, Khaligh A. Bi-Directional CLLC Converter With Synchronous Rectification for Plug-In Electric Vehicles. IEEE Transactions on Industry Applications. 2018;54(2):998-1005.

[10] He P, Khaligh A, editors. Design of $1 \mathrm{~kW}$ bidirectional half-bridge CLLC converter for electric vehicle charging systems. Power Electronics, Drives and Energy Systems (PEDES), 2016 IEEE International Conference on; 2016: IEEE.

[11] Steigerwald RL. A comparison of half-bridge resonant converter topologies. IEEE transactions on Power Electronics. 1988;3(2):174-82.

[12] Saleh S, Moloney C, Rahman M, editors. Developing a Non-dyadic MRAS for Switching DC-AC Inverters. Digital ignal Processing Workshop, 12th-Signal Processing Education Workshop, 4th; 2006: IEEE.

[13] Saleh S. The Implementation and Performance Evaluation of \$3〉hi \$ VS Wavelet Modulated AC-DC Converters. IEEE Transactions on Power Electronics. 2013;28(3):1096-106.

[14] Saleh S, Rahman MA. An introduction to wavelet modulated inverters: John Wiley \& Sons; 2011. 
[15] Saleh SA, Rahman A, Moloney CR. Wavelet modulated inverter. Google Patents; 2012.

[16] Saleh S, The wavelet modulation technique for $1 \varphi$ CHB multi-level DC-AC power electronic converters. Industry Applications Society Annual Meeting, 2017 IEEE; 2017: IEEE

\section{BIOGRAPHIES OF AUTHORS}
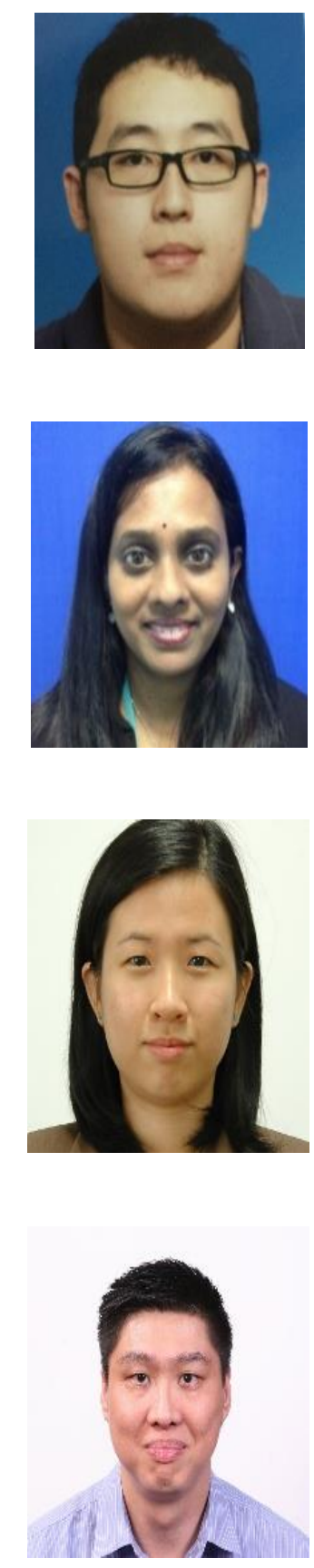

H. K. Chiu was born in Perak, Malaysia on Dec 1989. He completed his bachelor degree in Electrical and Electronic Engineering with University of Northumbria in 2012. He pursued and obtained his MEng in Power Systems from University Malaya in 2015.Currently he is pursuing his PhD with College of Engineering at Universiti Tenaga Nasional. His research interests are power electronics, electric vehicle, renewable energy and control systems. He is also a Member of the Institution of Engineering and Technology (IET) and the Institute of Electrical and Electronics Engineers (IEEE), and a Graduate Member of the Institution of Engineers Malaysia (IEM).

Agileswari K. Ramasamy was born in Taiping, Perak and received her B.Sc (Engineering) degree from Purdue University, USA in 1995 under the sponsorship of Yayasan Tenaga Nasional. She obtained her MSc. (Control System) from Imperial College, London in 2001 and $\mathrm{PhD}$ in Electrical Engineering from Universiti Tenaga Nasional (UNITEN), under the sponsorship of UNITEN. She is currently an Associate Professor in the Department of Electronics Communication Engineering at UNITEN and serving as a Deputy Dean of Research and Postgraduate for College of Engineering, UNITEN. She is also a Chartered Member of the Institution of Engineering and Technology (IET). She is currently active in research and consultancy in control system, power system, power quality, energy efficiency and renewable energy. She has headed several research projects to date and has successfully published several indexed journals. Nadia M. L. Tan received the B.Eng. (Hons.) degree from the University of Sheffield, Sheffield, U.K., in 2002, the M. Eng. degree from Universiti Tenaga Nasional, Kajang, Malaysia, in 2007, and the Ph.D. degree from Tokyo Institute of Technology, Tokyo, Japan, in 2010, all in electrical engineering. Since April 2017, she has been an Associate Professor in the Department of Electrical Power Engineering, Universiti Tenaga Nasional. Her current research interests include power conversion systems for energy storage, bidirectional isolated $\mathrm{dc}-\mathrm{dc}$ converters, multilevel cascaded inverters for renewable energy applications. She is a Chartered Engineer registered with Engineering Council, United Kingdom, a Member of the Institution of Engineering and Technology (IET) and the Institute of Electrical and Electronics Engineers (IEEE), and a Graduate Member of the Institution of Engineers Malaysia (IEM).

Matthew Y. W. Teow received the BSc (Electronic and Electrical) degree from the Robert Gordon University, Scotland, UK, in 1993, the MEng (Electrical) degree from Universiti Teknologi Malaysia, Johor, Malaysia, in 1999, and the PhD (Engineering) degree form the Multimedia University, Cyberjaya, Malaysia, in 2011.He is currently the Head of Research Management Centre of the First City University College, Selangor, Malaysia. His research interests include signal processing, information theory, and machine learning. He is a Professional Engineer with Practising Certificate (PEngPC) registered with the Board of Engineers Malaysia (BEM), Malaysia, a Chartered Engineer (CEng) registered with the Engineering Council (EngC), UK, a Corporate Member of the Institution of Engineers Malaysia (IEM), Malaysia, a member of the Institution of Engineering and Technology (IET), UK, and a senior member of the Institute of Electrical and Electronics Engineers (IEEE), US. 